\title{
The use of motivational interviewing skills for patient counselling in an interprofessional education learning simulation
}

\author{
Jonathon Pouliot ${ }^{1}\left(\mathbb{D}\right.$, Gabrielle Givens ${ }^{1}$, Susan Morley ${ }^{2}$, Kali Worley 1,3 , Jeff Lee ${ }^{1}$, Anne Lowery ${ }^{1}$, Autumn \\ Marshall ${ }^{1}$, Katie Watson ${ }^{1}$, Thomas M. Campbell ${ }^{1}$ \\ 1 Lipscomb University College of Pharmacy and Health Sciences, Nashville, Tennessee, United States \\ 2 Oregon State University College of Pharmacy, Corvallis, Oregon, United States \\ 3 Motivational Interviewing Network of Trainers, United States
}

\author{
Keywords \\ Dietetics \\ Interprofessional education \\ Motivational interviewing \\ Nursing \\ Pharmacy \\ Student perceptions

\section{Correspondence} \\ Jonathon Pouliot \\ Assistant Professor of Pharmacy \\ Practice \\ Lipscomb University College of \\ Pharmacy and Health Sciences \\ 1 University Park Dr. \\ Nashville \\ TN 37204 \\ jdpouliot@lipscomb.edu
}

\begin{abstract}
Objective: Healthcare training has increasingly focused on interprofessional education (IPE) to provide students opportunities to gain competencies and learn accountability. IPE was incorporated into the curriculum by creating a course for all health science. Motivational interviewing (MI) training was added to enhance the IPE process. The purpose of this study was to determine the effectiveness of $\mathrm{MI}$ training in patient counselling simulations.

Methods: A cohort of students enrolled in an IPE course were evaluated on MI skills before and after receiving training. $\mathrm{Ml}$ performance was coded using the Motivational Interviewing Treatment Integrity (MITI) 4.2.1 scoring system. A student perception survey was also administered. Results: A total of 210 students were included in the study. Results from the MITI indicate an improvement in the four global ratings after MI training in individual and group cohorts. For example, for the Cultivating global score, $0 \%$ reached at least a fair benchmark in the pre-training groups while 90\% (individual) and 50\% (group) reached the benchmark post-training. Student perceptions of IPE improved following MI training with more students strongly agreeing that working together was better for patients post-training (66.2\% vs $75.5 \%)$. Conclusion: The use of MI training in the setting of IPE setting appears to be beneficial. MI gives students a common language and approach to working with patients in an interprofessional setting.
\end{abstract}

\section{Introduction}

Interprofessional education and collaborative practice are major topics across healthcare education and interprofessional training programmes (Buring et al., 2009; WHO, 2010; Interprofessional Education Collaborative, 2016). Collaborative practice is a type of work involving interprofessional individuals who come together regularly to solve problems, provide services, and enhance health outcomes (Wilson et al., 2016). In order to improve patient outcomes and population health, healthcare training has increasingly focused on interprofessional education (IPE) as a means to provide students tangible, realistic, and meaningful opportunities to gain core competencies and learn shared accountability for patients (Wilson et al., 2016). The Interprofessional Education Collaborative (IPEC) has developed four key competencies to more formally define key goals of IPE (Interprofessional Education Collaborative, 2016). These include interprofessional teamwork and team-based practice, interprofessional communication practices, values and ethics for interprofessional practice, and roles and responsibilities for collaborative practice (Wilson et al., 2016). Benefits of implementing IPE into pharmacy curriculum include an overall enhanced understanding of professional responsibility, therefore enhancing the quality 
and continuity of care patients receive through collaboration. Student perceptions of IPE show improved understanding of both their own and other disciplines scope of practice, ability to work with others, and overall satisfaction (El-Awaisi et al., 2018). The Accreditation Council for Pharmacy Education (ACPE) now requires IPE as a standard for accreditation. Pharmacy students are required to be able to effectively communicate in interprofessional teams, engage in shared therapeutic decision making and participate on a team to facilitate direct patient care (ACPE, 2015). Indeed, involvement in interprofessional collaboration is a major goal noted throughout the ACPE 2016 Standards (ACPE, 2015). In Standard 11 of the ACPE Standard, three specific key elements are described as essential components of pharmacy education, these are: interprofessional team dynamics, interprofessional team education and interprofessional team practice (ACPE, 2015). Strategies focused on developing these components of interprofessional education are therefore essential to providing high quality training for today's pharmacist.

Motivational interviewing (MI) is a skill set developed initially for helping patients overcome addiction and has since been used in a variety of settings, including healthcare (Berger, \& Villaume, 2013; Christie, \& Channon, 2014; Salvo, \& Cannon-Breland, 2015; Eyler, Shvets, \& Blakely, 2016). This approach is patient-focused and specifically uses communication skills in order to motivate and empower patients to improve behaviour (Berger, \& Villaume, 2013). MI helps healthcare providers assess a patient's readiness to act on their health behaviour and then provides strategies for assisting the patient in overcoming ambivalence in order to make a positive life change (Berger, \& Villaume, 2013; ACPE, 2015; Salvo, \& Cannon-Breland, 2015; Interprofessional Education Collaborative, 2016; Wilson et al., 2016; El-Awaisi et al., 2018;). MI has been successfully used in addiction counseling, medication adherence, obesity, and other chronic health conditions (Berger, \& Villaume, 2013; Christie, \& Channon, 2014; Salvo, \& Cannon-Breland, 2015; Eyler, Shvets, \& Blakely, 2016).

In an effort to incorporate IPE into the curriculum, the study institution, a private university located in the southeastern United States, created a year-long Interprofessional Grand Rounds course for all health science programmes. The IPE course began in 2011 and includes senior nursing students, third-year student pharmacists, dietetic interns, exercise \& nutrition science masters students, and undergraduate nutrition students. The health science programmes were equally represented with faculty champions during the design, implemen- tation, and delivery of course content. The IPE course activities include didactic training, case-based group activities, and simulations. Limitations of inadequate faculty time, scheduling across multiple programmes, and other logistical challenges were minimised since all health science disciplines are united under a joint Dean (Matsumoto et al., 2020).

In 2014, the IPE course coordinators decided to incorporate a $\mathrm{Ml}$ training opportunity for all health sciences students enrolled in the course. Students were trained in the techniques of $\mathrm{MI}$ and assessed on their skills using a pre and post patient simulations. The goal was to enhance the IPE course experience, promote student teamwork, and provide an introduction to Ml skills that can be utilised in interprofessional collaborative practice (Matsumoto et al., 2020).

The purpose of this study was to determine the effectiveness of motivational interviewing training on healthcare student performance in a simulated patient counselling session for individual students and interprofessional student groups.

\section{Methods}

This pragmatic retrospective cohort study was approved by the University's Institutional Review Board (IRB). Following IRB approval, all students enrolled in the IPE course were given written informed consent documents and provided with a clear explanation of the study design and objectives. A total of 210 students, already enrolled in the IPE course, completed the voluntary informed consent for the study. Due to the large class size and limited faculty resources, only a portion of the students were randomly assessed; This was done using recorded simulated patient counselling sessions before the $\mathrm{MI}$ training began, and four months after completion of the MI training during the spring semester. Students not enrolled in both the autumn and spring terms of the IPE course were excluded from the assessment simulations but were included in the course evaluation of student IPE perceptions.

The course coordinators collaborated with an experienced Motivational Interviewing Network of Trainers (MINT) member to conduct the $\mathrm{MI}$ training and code the recorded the simulated patient sessions. MINT is an international organisation of trainers who have completed the required $\mathrm{Ml}$ training coursework endorsed or sponsored by the organisation (MINT Board of Directors, 2015). Although MINT does not currently license or certify their member 

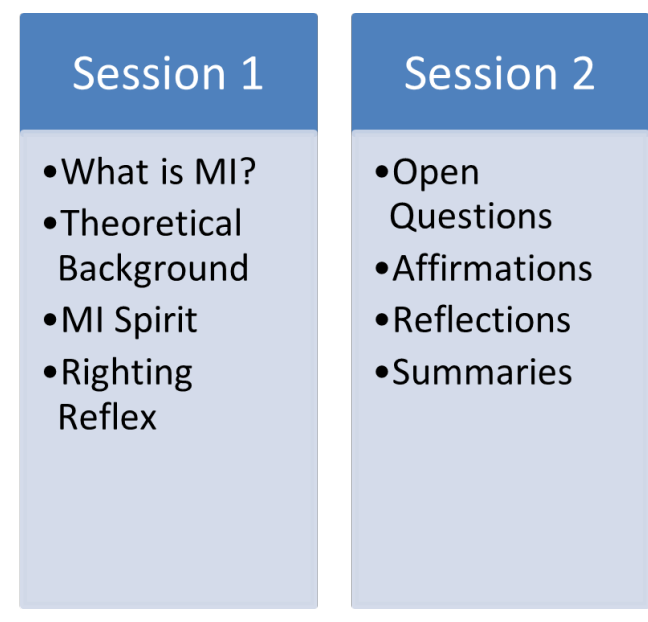
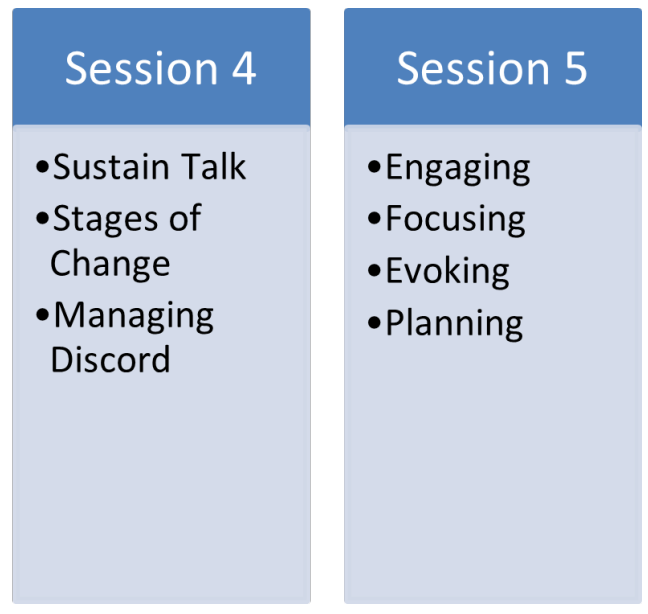

Figure 1: IPE MI Training Sessions \& Topics

trainers, the educational programmes and membership 'promote quality applications of motivational interviewing across cultures, languages, and contexts' (MINT Board of Directors, 2015). IPE coordinators often employ MI trainers to ensure quality content and and trained coders for the proper utilisation of the Motivational Interviewing Treatment Integrity (MITI) scale when coding recorded simulations (White, Gazewood, \& Mounsey, 2007; Molander et al., 2017; Matsumoto et al., 2020).

Student MI training was completed during the five IPE sessions, at 1.5 hours each, scheduled over the autumn term (see Figure 1). The MINT member conducted all the IPE MI training sessions and guided student group activities. The MINT member also supplied MI student workbooks for note-taking and student reflections.

For their pre- and post- $\mathrm{MI}$ training simulations, 20 students were randomly assigned to function as individuals and the remainder were assigned to IPE teams of four to five students each (40 groups total). Using individual students and IPE teams for simulation experiences was a tool implemented to highlight the importance of good communication skills with patients and team collaboration in healthcare. From these preassigned individuals and teams, ten individual counselling sessions and ten group counselling sessions were randomly selected to be recorded pre- and post- MI training. The institution used current faculty to play the part of the simulated patient. All faculty patient actors received a two hour orientation training with the MINT member to promote a standardised simulation experience. Every simulated counselling session was recorded using university-issued iPad and uploaded to password-protected shared drive using numerical identifiers in order to de-identify the groups. Student and team MI performance was coded by the MINT trainer using the Motivational Interviewing Treatment Integrity (MITI) 4.2.1 scoring system. Students not selected for a recorded assessment simulations conducted the same patient counselling sessions with fellow students by role playing.

The first simulation, before the MI training began, was used to establish student Ml skills at baseline. This was important to ascertain since the skills and training among the IPE students was very diverse. The first simulation activity involved a paediatric patient whose parents were reluctant to immunise their child (see Figure 2). During the simulation, individual students and interprofessional groups were asked to counsel the patient's parent on the need for immunisation.

Following the term-long $\mathrm{Ml}$ training in the autumn, a second simulation activity was performed in the spring to assess the students, ten individuals and ten IPE teams, with a new patient scenario of a non-compliant Type II Diabetes Mellitus patient. The course coordinators determined that a new but similar patient scenario should be utilised for the post $\mathrm{MI}$ training assessment. The same procedures were used for conducting, recording and scoring the simulations with the MITI 4.2.1 coding system.

Positive changes in patient behaviours are the ultimate measure of success for $\mathrm{Ml}$ interventions, but this approach is not always feasible in educational environments where students are not counselling live patients (Matsumoto et al., 2020). IPE programmes often utilise standardised patient encounters or various role-playing techniques to develop Ml skills in their student populations (Molander et al., 2017; Matsumoto et al., 2020). There are various tools to assess skills fidelity in MI training programmes with the Motivational Interviewing Treatment Integrity (MITI) tool being is the most commonly used (Gill, Oster, \& Lawn, 2020). The MITI scale is a validated instrument used to 
Grand Rounds MITI Case: Immunizations (Parent)

PR is an 11 month old female who is brought to clinic today for a checkup by her parent. She has had no illnesses or complications thus far and has not had any allergies reported. She is her parent's second child and their first child is a 6 year-old who has recently been formally diagnosed with Autism.

While PR has received all of her vaccinations as scheduled according to CDC recommendations, her parent is now refusing the next scheduled vaccinations. Her next doses are a first dose of varicella, first dose of MMR (measles, mumps, and rubella), and first dose of Hepatitis A. Her parents have recently been researching Autism because of PR's brother being diagnosed and have come across articles, documentaries and news releases discussing the connection between vaccinations and autism as well as other potential complications associated with vaccinations. Because of this information, they are now wanting to withhold all vaccines from $P R$ and are refusing the next series of vaccines. They are concerned about PR becoming autistic and don't think that measles, mumps, rubella, or hepatitis A are very common and risk is low. They also state that they both had chicken pox as children and 'turned out fine' so they don't think the varicella series is important.

You are tasked with discussing these concerns with PR's parent in an attempt to correct misinformation and give accurate information about the risks of children not getting vaccines.

Figure 2: Standardised patient case

assess $\mathrm{MI}$ skills in training programmes and research studies (Moyers et al., 2005; Moyers et al., 2016; Szczekala et al., 2018; Gill, Oster, \& Lawn, 2020).

MITI scoring of the student simulations was conducted according to the MITI coding manual version 4.2.1 by the experienced MINT member (Moyers et al., 2005; Moyers et al., 2016). The Motivational Interviewing Treatment Integrity (MITI) 4.2.1 coding system has two domains; a global rating component and a behavioural count component. The MITI coding system provides a review of the overall quality rating of the interaction (global score with four domains) and a captures the number of specific behaviours displayed by the person(s) being assessed (behavioural count). The global rating incorporates both technical and relational skills that practitioners use in conversations with a patient. The technical rating specifically assesses to what extent a practitioner cultivates change talk and softens sustain talk to resolve patient ambivalence. The relational rating specifically assesses to what extent the practitioner demonstrates both partnership and empathy for the patient. The practitioner is rated on each global score for cultivating change talk, softening sustain talk, partnership and empathy (see Figure 3). The behaviour counts serves to capture the number of instances a particular behaviour is displayed by the practitioner during the session. Behaviour counts are tallied into categories.

Global scores are coded on a scale of 1 to 5 , where 1 is low and 5 is high, and are compared with 'fair' and 'good' benchmarks based on MITI coding standards. Fair benchmarks indicate a beginner's Ml skillset while a good benchmarks indicates a demonstration of proficient MI skills. The authors study results for global scores are reported as a percentage of students, individual and student teams per simulation session, that met either benchmarks. Table I indicates the specific 'Fair' and 'Good' benchmarks for each of type of behaviour the practitioner demonstrated. In reference to behaviour counts as part of the MITI coding system, instances of persuasion and confronting are considered behaviours to be avoided while other behaviour counts are considered behaviours to be encouraged or to be used sparingly (Table I) (Christie, \& Channon, 2014). 


\begin{tabular}{|c|c|c|c|c|}
\hline \multicolumn{5}{|c|}{ Cultivating Change Talk } \\
\hline Low & & & & High \\
\hline 1 & 2 & 3 & 4 & 5 \\
\hline $\begin{array}{l}\text { Clinician shows no } \\
\text { explicit attention to, } \\
\text { or preference for, } \\
\text { the client's language } \\
\text { in favor of changing }\end{array}$ & $\begin{array}{l}\text { Clinician sporadically } \\
\text { attends to client } \\
\text { language in favor of } \\
\text { change - frequently } \\
\text { misses opportunities } \\
\text { to encourage change } \\
\text { talk }\end{array}$ & $\begin{array}{c}\text { Clinician often } \\
\text { attends to the client's } \\
\text { language in favor of } \\
\text { change, but misses } \\
\text { some opportunities } \\
\text { to encourage change } \\
\text { talk }\end{array}$ & $\begin{array}{c}\text { Clinician } \\
\text { consistently attends } \\
\text { to the client's } \\
\text { language about } \\
\text { change and makes } \\
\text { efforts to encourage } \\
\text { it }\end{array}$ & $\begin{array}{l}\text { Clinician shows a } \\
\text { marked and } \\
\text { consistent effort to } \\
\text { increase the depth, } \\
\text { strength, or } \\
\text { momentum of the } \\
\text { client's language in } \\
\text { favor of change }\end{array}$ \\
\hline
\end{tabular}

Figure 3: Example of MITI 4.2.1 Scoring System

Table I: MITI 4.2.1 Scoring System

\begin{tabular}{|c|c|c|}
\hline Global Scores & $\begin{array}{l}\text { Fair' Benchmarks } \\
\text { (out of 5) }\end{array}$ & $\begin{array}{l}\text { Good' Benchmarks } \\
\text { (out of 5) }\end{array}$ \\
\hline Cultivating & 3 & 4 \\
\hline Softening & 3 & 4 \\
\hline Partnership & 4 & 5 \\
\hline Empathy & 4 & 5 \\
\hline \multicolumn{3}{|l|}{ Behavior Counts } \\
\hline Giving information & To be used sparingly & \\
\hline Persuasion & To be avoided & \\
\hline Persuade WITH Permission & To be encouraged & \\
\hline Questions & To be used sparingly & \\
\hline Simple Reflection & To be encouraged & \\
\hline Complex Reflection & To be encouraged & \\
\hline Affirmation & To be encouraged & \\
\hline Seeking Collaboration & To be encouraged & \\
\hline Emphasize Autonomy & To be encouraged & \\
\hline Confronting & To be avoided & \\
\hline
\end{tabular}

To assess student experiences, students were invited to complete pre- and post- survey on their perceptions of the course, other professional students, and motivational interviewing. Some basic student demographic data was included in the course survey and students were asked to identify their field of study. Participation in the survey was not required by the course coordinators. Due to the size of the study, a statistical analysis was not planned and results are reported using descriptive statistics only.

\section{Results}

A total of 210 students were included in the course (Table II), mostly consisting of nursing, pharmacy and nutrition/ dietetic students. Of the 210 students enrolled in the course, 20 students were assigned to individual groups each semester and the rest were assigned to groups of four to five students ( 40 groups total). From these individuals and groups, ten individual counselling sessions and ten group counselling sessions were randomly selected to be scored on the MITI coding system before and after the semester-long $\mathrm{Ml}$ training. No other demographic data were collected on all students beyond their individual disciplines however students who completed the voluntary surveys did submit age and ethnicity information.

Table II: IPE Health Sciences Student Discipline Summary

\begin{tabular}{ll}
\hline Student disciplines & IPE Course Enrolment \\
\hline Nursing (BSN) & $30.5 \%(n=64)$ \\
Pharmacy (PharmD) & $31.4 \%(n=66)$ \\
Exercise Science (MS) & $1.8 \%(n=3)$ \\
Dietetic Intern & $7.1 \%(n=15)$ \\
Nutrition (BS) & $29.5 \%(n=62)$ \\
Total & 210 \\
\hline
\end{tabular}

Results from MITI coding indicate an improvement in both global ratings and behaviour counts after MI training was implemented. For the global ratings, both individuals and interprofessional student group scores improved with a larger proportion of subjects meeting at least the minimum benchmark of fair $\mathrm{MI}$ practice in all categories with the exception of empathy. Table III summarises the percentage of global scores reaching Fair or better benchmark for the individual and group interviews.

Additionally, the behaviour counts improved in both individual and interprofessional student group sessions. In general, behaviour counts of persuasion and confronting were lower or unchanged from pre- to post-training and encouraged behaviour counts were increased after $\mathrm{MI}$ training (see Figures $4 a$ and $4 b$ ). When comparing the individual and group behaviour counts, the groups had more giving information counts than the individuals, however other behavioural counts were similar between the two cohorts. 
Table III: Performance of Individuals and Groups Preand Post-Training on Global Scores System

\begin{tabular}{lllll}
\hline $\begin{array}{l}\text { Global Score } \\
\text { Category }\end{array}$ & $\begin{array}{l}\text { Individual Interviews } \\
\text { Percentage } \\
\text { or higher benchmark }\end{array}$ & $\begin{array}{l}\text { Group Interviews } \\
\text { meeting 'Fair' }\end{array}$ & $\begin{array}{l}\text { Percentage meeting 'Fair' or } \\
\text { higher benchmark }\end{array}$ \\
& Pre-Training Post-Training & Pre-Training & Post-Training \\
\hline Cultivating & $0 \%$ & $50 \%$ & $0 \%$ & $90 \%$ \\
Softening & $40 \%$ & $100 \%$ & $60 \%$ & $90 \%$ \\
Partnership & $0 \%$ & $10 \%$ & $0 \%$ & $40 \%$ \\
Empathy & $0 \%$ & $0 \%$ & $0 \%$ & $0 \%$ \\
\hline
\end{tabular}

Finally, results from the pre- and post-course student survey are presented in Table IV. There was an improvement in student perceptions of IPE and the importance of other health professions after completing the course. Additionally, there was a greater appreciation for the need to overcome assumptions and prejudices that health professions have for other disciplines after completing the $\mathrm{Ml}$ training course. There were no differences seen in terms of student satisfaction with the course content prior to and after the implementation of the course.

\section{Discussion}

Motivational interviewing is a skill taught across multiple disciplines and can be used as topic for interprofessional education in professional programmes and clinical settings (Molander et al., 2017; Nagelkerk et al., 2018; Matsumoto et al., 2020). In the clinical setting, Wilson and colleagues found the knowledge of each profession's capacity and respecting the contributions of others on the team, influenced the quality of interprofessional collaborative practice (Wilson et al., 2016). For healthcare students, MI training provides an opportunity to learn a skill set that can be used on clinical rotations and future interprofessional collaborate care settings. $\mathrm{MI}$ training in IPE has been shown to be a valuable topic to address the IPEC competencies in healthcare education. Through MI training, students gain knowledge about their role and the role of other professions on their team. This can increase how team members are valued and respected for the skills and knowledge they contribute to the team. Ml also provides the opportunity to practice communication and teamwork skills in group activities and simulations (Matsumoto et al., 2020). IPE students have also reported increased confidence in their ability to use $\mathrm{Ml}$ in a patient care setting after receiving training (Matsumoto et al., 2020; Larson, \& Martin, 2021).
In this study, the implementation of MI training in the IPE course resulted in improvements in the motivational interviewing skills of the students. For the global ratings, there was a higher percentage of students reaching minimum benchmarks for Ml practice in three of the four categories. Neither individual student nor the interprofessional student teams reached minimum benchmarks in empathy before or after MI training. It should be noted that the benchmark for the empathy category is more difficult to obtain and it is common for even experienced professionals with $\mathrm{MI}$ training to take years to develop this competency.

In terms of behaviour counts, there was a general trend in minimising avoidable behaviours and increasing desirable behaviours after $\mathrm{MI}$ training. Comparing individual students to interprofessional student teams counts, there were higher results of giving information, simple reflection, and affirmation counts in the student teams and a larger change from pre-training to post-training. This may be due to having more professionals represented on an interprofessional team discussing issues with a patient. An interprofessional team approach to patient counselling may provide a wide-range of information with the varied perspectives of each member being convey to the patient. It could also be due to the student teams learning how to function as a group to accomplish their goals, but future research would be needed to address these findings. Other behaviour counts and differences in pre-training and post-training were similar between individual students and student teams.

Strengths of this study include it being a pragmatic evaluation of IPE course experience in real time. This study was able to identify the value and immediate application of $\mathrm{MI}$ training on IPE patient counselling scenarios. While $\mathrm{MI}$ is typically performed by an individual practitioner, one of the unique aspects of this study was to observe a group of healthcare students collaborating during a patient simulation counselling session to develop their Ml skills. Future research is needed to see how the application of $\mathrm{Ml}$ training of interprofessional student teams achieves IPEC competencies.

There are various limitations in this study. This study was conducted at one institution, enrolled a limited variety of healthcare disciplines, and had a small study population ( $\mathrm{n}$ = 210). Faculty resources only allowed a small number of students to be assessed using a pre and post MI training simulated patient encounters vs the entire class. Faculty were utilised as the simulated patients since standardised patients were not available. While case training was provided to the faculty by the MINT member, this could have resulted in differences in performance and variability 


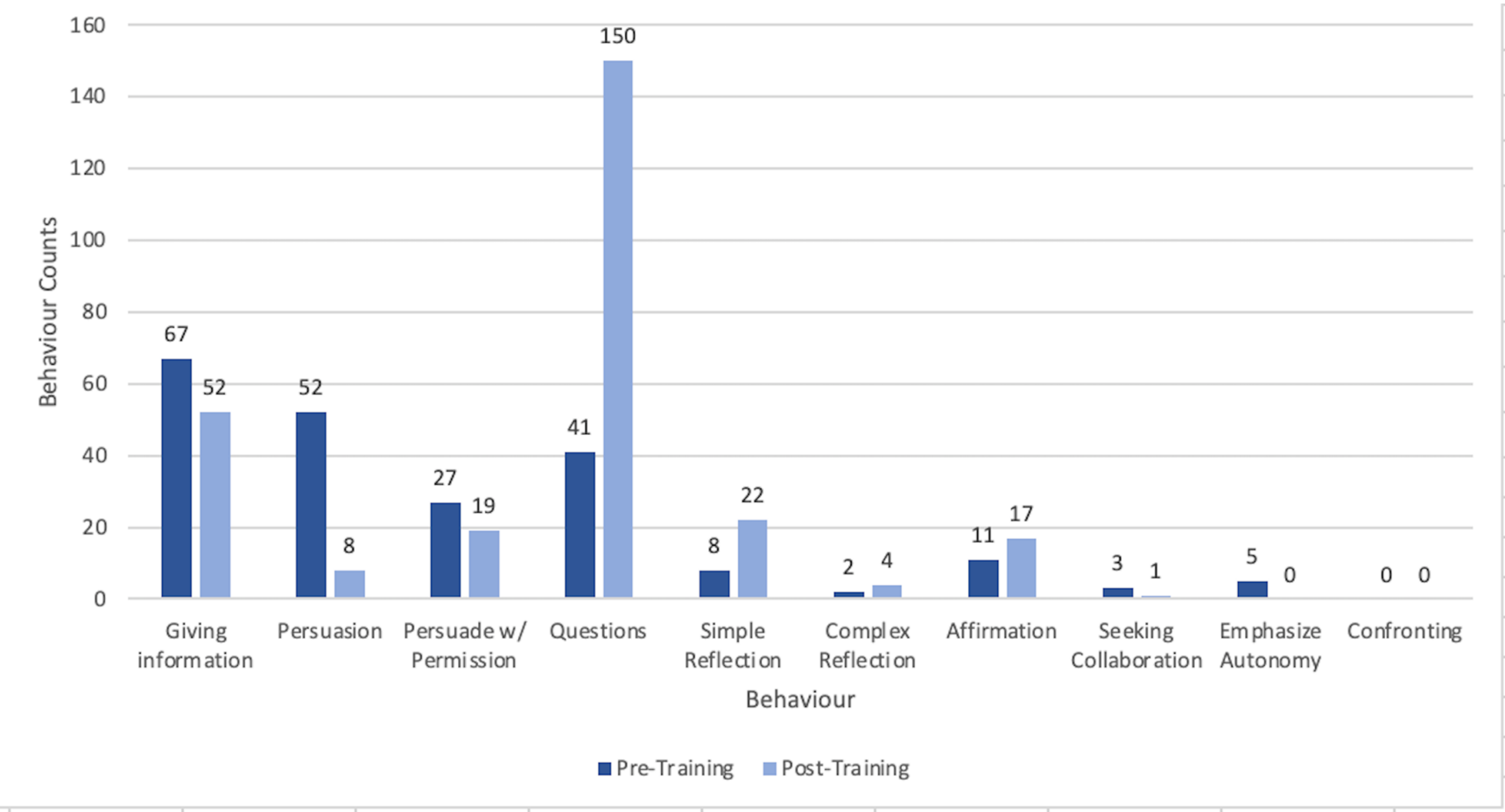

Figure 4a: Individual behaviour counts

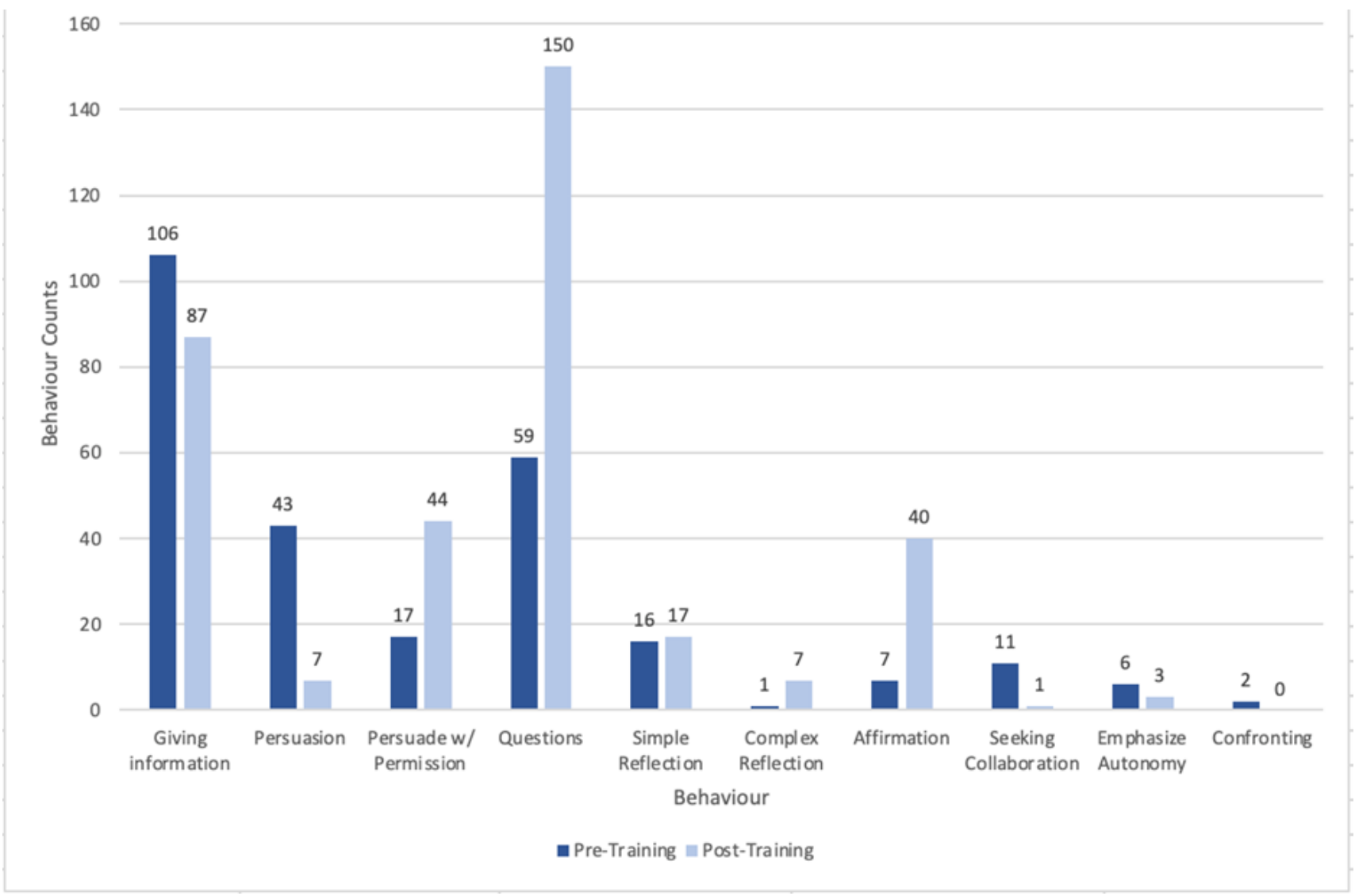

Figure 4b: Group behaviour counts 
Table IV: Student course perceptions survey

\begin{tabular}{|c|c|c|}
\hline \multicolumn{3}{|c|}{ Student survey result } \\
\hline & $\begin{array}{l}\text { Pre-Study } \\
(n=154)\end{array}$ & $\begin{array}{l}\text { Post-Study } \\
\text { ( } \mathrm{n}=49)\end{array}$ \\
\hline Female, \% (n) & $77.3 \%(119)$ & $65.3 \%(32)$ \\
\hline \multicolumn{3}{|l|}{ Discipline } \\
\hline Dietetic Intern & $7.8 \%(12)$ & $6.1 \%(3)$ \\
\hline Nursing Student & $35.7 \%(55)$ & $16.3 \%(8)$ \\
\hline Nutrition Student & $16.2 \%(25)$ & $6.1 \%(3)$ \\
\hline Pharmacy Student & $40.3 \%(62)$ & $71.4 \%(35)$ \\
\hline \multicolumn{3}{|l|}{ Age Range } \\
\hline $19-22$ & $46.1 \%(71)$ & $20.4 \%(10)$ \\
\hline $23-32$ & $46.8 \%(72)$ & $69.4 \%(34)$ \\
\hline $33-42$ & $7.1 \%(11)$ & $10.2 \%(5)$ \\
\hline \multicolumn{3}{|l|}{ Ethnicity } \\
\hline Caucasian & $78.6 \%(121)$ & $77.6 \%(38)$ \\
\hline African American & $7.1 \%(11)$ & $10.2 \%(5)$ \\
\hline Other & $14.3 \%(22)$ & $12.2 \%(6)$ \\
\hline \multicolumn{3}{|c|}{ Survey question responses pertinent to IPE } \\
\hline \multicolumn{3}{|c|}{$\begin{array}{l}\text { Patients would ultimately benefit if health sciences students worked } \\
\text { together to solve patient problems }\end{array}$} \\
\hline Strongly agree & $66.2 \%(102)$ & $75.5 \%(37)$ \\
\hline Agree & $32.5 \%(50)$ & $24.5 \%(12)$ \\
\hline Neutral & $1.3 \%(2)$ & $0 \%(0)$ \\
\hline \multicolumn{3}{|c|}{$\begin{array}{l}\text { Shared learning with other health sciences students will increase my } \\
\text { ability to understand clinical problems }\end{array}$} \\
\hline Strongly agree & $53.9 \%(83)$ & $61.2 \%(30)$ \\
\hline Agree & $42.2 \%(65)$ & $36.7 \%(18)$ \\
\hline Neutral & $3.3 \%(5)$ & $0 \%(0)$ \\
\hline Disagree & $0.7 \%(1)$ & $2 \%(1)$ \\
\hline \multicolumn{3}{|c|}{$\begin{array}{l}\text { Prejudices and assumptions about health professionals from o } \\
\text { disciplines get in the way of delivery of health care }\end{array}$} \\
\hline Strongly agree & $23.4 \%(36)$ & $27.1 \%(13)$ \\
\hline Agree & $50 \%(77)$ & $54.2 \%(26)$ \\
\hline Neutral & $15.6 \%(24)$ & $12.5 \%(6)$ \\
\hline Disagree & $8.4 \%(13)$ & $4.2 \%(2)$ \\
\hline Strongly Disagree & $2.6 \%(4)$ & $2.1 \%(1)$ \\
\hline
\end{tabular}

in the individuals' and student teams' counselling sessions. The MITI 4.2.1 coding system was designed to assess individual $\mathrm{Ml}$ performance and was applied to both individuals and interprofessional student teams in this study. Using MITI 4.2.1 to evaluate groups is fairly novel approach but the developers of the coding system approved of its use in this situation. The MINT member personally coded all student simulations but Ideally we would have the recorded sessions double coded to reduce bias. Due to the small sample size and pragmatic nature of the study, additional comparisons (group versus individual performance, etc.) was not feasible. Finally, the survey used in this course was optional and resulted in a decreased response post-training.

This study confirms the viability of motivational interviewing training in an IPE course and shows that MI training can be beneficial for individual students' and interprofessional student teams' performance in patient simulations. Motivational interviewing is a skill that must be practiced and refined over time (Miller, \& Rollnick,
2009). Matsumoto and colleagues (2020) reported that IPE students, comprised of nine disciplines training in $\mathrm{MI}$, reported better learning outcomes when provided with more opportunities to regularly practice their $\mathrm{Ml}$ skills versus increasing the time in didactic sessions. In the authors study findings students were assessed after their MI training was complete (four months prior) and they did not have the opportunity to practice a comprehensive patient interview beyond their pre and post simulations. In addition, students did not receive formal feedback from faculty or an MITI review of their MI skills during the course to improve their methods. (White, Gazewood, \& Mounsey, 2007; Miller, \& Rollnick, 2009; Larson, \& Martin, 2021). Additional MI practice sessions could improve student perceptions, confidence, and Ml skills.

\section{Conclusion}

The use of motivational interviewing training in the setting of IPE appears to be beneficial and should be considered in training programmes for healthcare professionals. The use of $\mathrm{Ml}$ training improved student perceptions on the importance of teamwork and served as an introduction to developing $\mathrm{MI}$ skills. $\mathrm{MI}$ training in IPE provides an opportunity to learn a skill set that can be used on clinical rotations and future interprofessional collaborate care settings. Further research on the use of $\mathrm{MI}$ in IPE is warranted, particularly in the area of how student $\mathrm{MI}$ training translates to clinical practice.

\section{Conflict of interests}

Each of the authors of this manuscript report being affiliated with the organisation where the research was conducted at the time it was conducted. No authors report any financial or other conflicts of interest.

\section{References}

ACPE (Accreditation Council for Pharmacy Education). (2015) Accreditation standards and key elements for the professional program in pharmacy leading to the doctor of pharmacy degree (online). Available from: https://www.acpe-accredit.org/pdf/Standards2016FINAL.pdf

Berger, B.A, \& Villaume, W. (2013) Motivational interviewing for health care professionals: a sensible approach. 2nd ed. Washington, DC: American Pharmacists Association.

Buring, S.M., Bhushan, A., Broeseker, A., Conway, S., Duncan-Hewitt, W., Hansen, L., \& Westberg, S. (2009). Interprofessional education: definitions, student competencies, and guidelines for 
implementation. American journal of pharmaceutical education, 73(4), 59. https://doi.org/10.5688/aj730459

Christie, D., \& Channon, S. (2014) The potential for motivational interviewing to improve outcomes in the management of diabetes and obesity in pediatric and adult populations: a clinical review. Diabetes, obesity \& metabolism, 16(5), 381-387. https://doi.org/10.1111/dom. 12195

El-Awaisi, A., Joseph, S., Hajj, M., \& Diack, L. (2018). A comprehensive systematic review of pharmacy perspectives on interprofessional education and collaborative practice. Research in social \& administrative pharmacy : RSAP, 14(10), 863-882. https://doi.org/10.1016/j.sapharm. 2017.11.001

Eyler, R., Shvets, K., \& Blakely, M. (2016) Motivational Interviewing to Increase Postdischarge Antibiotic Adherence in Older Adults with Pneumonia. The Consultant pharmacist : the journal of the American Society of Consultant Pharmacists, 31(1), 38-43. https://doi.org/10.4140/ TCP.n.2016.38

Gill, I., Oster, C, \& Lawn, S. Assessing competence in health professionals use of motivational interviewing: A systematic review of training and supervision tools. Patient education and counseling, 103(3), 473-483. https://doi.org/10.1016/j.pec.2019.09.021

Interprofessional Education Collaborative. (2016). Core competencies for interprofessional collaborative practice: 2016 update. Washington, DC: Interprofessional Education Collaborative.

Larson, E., \& Martin, B.A. (2021) Measuring motivational interviewing self-efficacy of pre-service students completing a competency-based motivational interviewing course. Exploratory Research in Clinical and Social Pharmacy. 1, 100009. https://doi.org/10.1016/j.rcsop. 2021.100009

Matsumoto, A.N., DeSena, D., Kuzma, E.K., Bostwick, J.R., Furgeson, D., Yorke, A., \& Inglehart, M.R. (2020) The evolution of an interprofessional education motivational interviewing workshop: Finding the right balance. Journal of Interprofessional Education \& Practice. 20, 100342. https:// doi.org/10.1016/j.xjep.2020.100342

MINT Board of Directors. (2015) How to Become a MINT Member. v. 1.3 (online). Available at: https://motivationalinterviewing.org/sites/default/ files/mint_pathways_1.3_1.pdf

Molander, R., Hodgkins, K., Johnson, C., White, A., Frazier, E., \& Krahn, D. (2017). Interprofessional Education in Patient Aligned Care Team Primary Care-Mental Health Integration. Federal practitioner : for the health care professionals of the VA, DoD, and PHS, 34(6), 40-48.

Moyers, T.B., Rowell, L.N., Manuel, J.K., Ernst, D., Houck, J.M. (2016) The Motivational Interviewing Treatment Integrity Code (MITI 4): Rationale, preliminary reliability and validity. Journal of Substance Abuse Treatment. 65, 36-42. https://doi.org/10.1016/j.jsat.2016.01.001

Moyers, T.B., Martin, T., Manuel, J.K., Hendrickson, S.M., \& Miller, W.R. (2005). Assessing competence in the use of motivational interviewing. Journal of substance abuse treatment, 28(1), 19-26. https://doi.org/10.1016/j.jsat.2004.11.001

Nagelkerk, J., Benkert, R., Pawl, B., Myers, A., Baer, L.J., Rayford, A., Berlin, S.J., Ferbert, K., Moore, H., Armstrong, M., Murray, D., Boone, P.D., Masselink, S., \& Jakstys, C. (2018). Test of an interprofessional collaborative practice model to improve obesity-related health outcomes in Michigan. Journal of Interprofessional Education \& Practice. 11, 43-50. https://doi.org/10.1016/j.xjep.2018.02.001
Miller, W., Rollnick, S. (2009) Ten Things that Motivational Interviewing Is Not. Behavioural and cognitive psychotherapy. 37, 129-140. https:// doi.org/10.1017/S1352465809005128

Salvo, M., \& Cannon-Breland, M. (2015) Motivational interviewing for medication adherence. Journal of the American Pharmacists Association : JAPhA, 55(4), e354-e363. https://doi.org/10.1331/JAPhA.2015.15532

White, L.L., Gazewood, J.D., Mounsey, A.L. (2007) Teaching students behavior change skills: description and assessment of a new Motivational interviewing curriculum. Medical Teacher. 29(4), e67-e71. h t t p s : / / doi.org/10.1080/01421590601032443

Szczekala, K., Wiktor, K., Kanadys, K., Wiktor, H. (2018) Benefits of Motivational Interviewing Application for Patients and Healthcare Professionals. Polish Journal of Public Health. 128, 170-173. https:// doi.org/10.2478/pjph-2018-0034

WHO (World Health Organization). (2010) WHO Framework for Action on Interprofessional Education and Collaborative Practice. Available at: https://www.who.int/publications/i/item/framework-for-action-oninterprofessional-education-collaborative-practice

Wilson, A.J., Palmer, L., Levett-Jones, T., Gilligan, C., \& Outram, S. (2016) Interprofessional collaborative practice for medication safety: Nursing, pharmacy, and medical graduates' experiences and perspectives. Journal of Interprofessional care, 30(5), 649-654, https://doi.org/ 10.1080/13561820.2016.1191450 